\title{
Bacterial infection of endometrial stromal cells influences bovine herpesvirus 4 immediate early gene activation: a new insight into bacterial and viral interaction for uterine disease
}

\author{
Gaetano Donofrio, Lara Ravanetti, Sandro Cavirani, Shan Herath ${ }^{1}$, Antonio Capocefalo \\ and lain Martin Sheldon ${ }^{1}$ \\ Dipartimento di Salute Animale, Facoltà di Medicina Veterinaria, Università di Parma, Sezione di Malattie Infettive \\ degli Animali, via del Taglio 8, 43100 Parma, Italy and ${ }^{1}$ Department of Veterinary Clinical Sciences, Royal Veterinary \\ College, University of London, Royal College Street, London NW1 OTU, UK
}

Correspondence should be addressed to G Donofrio; Email: gaetano.donofrio@unipr.it

\begin{abstract}
Experimental infection with the $\gamma$-herpesvirus bovine herpesvirus 4 (BoHV-4) rarely establishes disease, yet BoHV-4 is commonly associated with uterine disease in cattle. Uterine disease involves co-infection with bacteria such as Escherichia coli, which stimulate the production of prostaglandin $\mathrm{E}_{2}\left(\mathrm{PGE}_{2}\right)$ by endometrial cells. BoHV-4 replication depends on immediate early 2 (IE2) gene transactivation and, in the present study, $\mathrm{PGE}_{2}, E$. coli or its lipopolysaccharide upregulated the IE2 gene promoter in uterine cells. Bacterial co-infection is important for BoHV-4 uterine disease.

Reproduction (2008) 136 361-366
\end{abstract}

\section{Introduction}

Abortion may follow infection with a variety of $\alpha-, \beta$ - and $\gamma$-herpesviruses, but viral causes of uterine disease are seldom investigated in cattle. Although postpartum metritis affects up to $40 \%$ of cattle, causing considerable infertility and economic loss, it has been assumed that most diseases are of bacterial origin, and virus isolation or serology is rarely considered (Sheldon \& Dobson 2004). The first isolation of bovine herpesvirus 4 (BoHV-4) from a case of bovine metritis was reported in the USA (Park \& Kendrick 1973). Later, several other isolates were obtained from cows with reproductive disorders from different countries, including Italy (Castrucci et al. 1986). In Belgium, BoHV-4 seroprevalence was associated with postpartum metritis and chronic infertility of cattle (Czaplicki \& Thiry 1998). Postpartum metritis has also been associated with BoHV4 in the USA (Frazier et al. 2002), Spain (Monge et al. 2006), and Serbia (Nikolin et al. 2007). There is a lacuna in the knowledge about the direct correlation between viral infection and uterine pathology.

The BoHV-4 immediate early (IE) genes are expressed immediately during cell infection, do not require prior viral protein synthesis for their expression, and their expression is mediated by the pool of transcription factors made by the cell, already present at the moment of infection and able to transactivate at the transcriptional level of the IE promoters. BoHV-4 IE2 protein (replication and transcription activator homologous, Rta) encoded by open reading frame 50 (ORF 50) is well conserved among $\gamma$-herpesviruses (Zimmermann et al. 2001). Rta expression plays a primary role in initiating viral lytic replication, not only during reactivation of latently infected non-permissive cells but also during de novo infection of permissive cells (van Santen 1993, Donofrio et al. 2004). Viruses are restricted to using the metabolic and biosynthetic pathways of the cells that they infect. These pathways vary between cell types, lineage, stage of differentiation, and with the state of cell activation. There are many examples of viruses that replicate in specific cells and at particular stages of cell growth, differentiation, or activation. This includes the reactivation of cytomegalovirus when host cells differentiate into macrophages, initiation of papillomavirus replication by keratinocytes, and replication of minute virus in testicular cells. The key mechanism mediating these effects is the regulation of viral gene expression at the transcriptional level by host cell factors. In previous studies (Donofrio et al. $2007 a, 2007 b$ ), the interaction, tropism, and outcome of BoHV-4 challenge of endometrial epithelial and stromal cells were investigated. In the present report, to further investigate the mechanisms associated with endometrial tropism, a molecular switch involving the 
viral IE2 gene has been associated with extracellular stimuli belonging to the intrauterine microenvironment, and not as bacterial contamination.

\section{Results}

\section{Activation of BoHV-4 promoter in BES cells}

To be able to quantify transactivation of the IE2 promoter in bovine endometrial stromal (BES) cells, a luciferase reporter construct was developed by sub-cloning the BoHV-4 IE2 promoter in front of the pGL3 Luciferase reporter vector (Promega) ORF to generate pIE2prom-Luc (Fig. 1a). BES cells were co-transfected with pIE2 prom-Luc or pGL3 empty vector as a negative control, and pRK-Renilla (Promega) to normalize the efficiency of

(a)

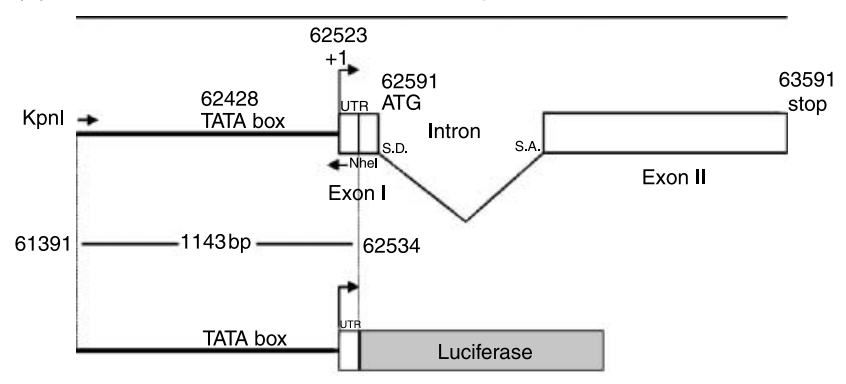

pIE2prom-Luc

(b)

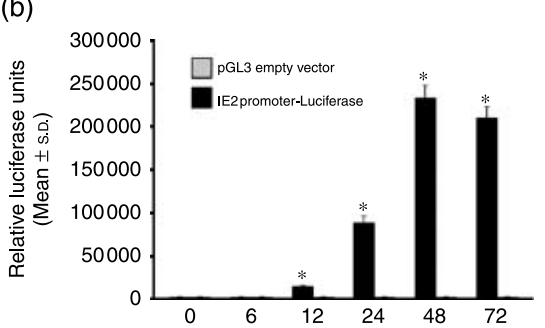

Figure 1 (a) Diagram showing the genomic region containing BoHV-4 IE2 gene (not to scale), where the exon II (white box) contains most of the IE2 ORF, except the translation initiation codon contained in the exon I (white box) together with the $5^{\prime}$ UTR. The splicing donor (SD) and splicing acceptor (SA) sites are indicated. During splicing, the intron is removed and the two exons (I and II) are joined together to generate the IE2 ORF. Sense and antisense primers used for the PCR amplification of the promoter region sequence (1143 bp) are indicated by arrows, spanning the full promoter containing the TATA box and the first 15 non-coding nucleotides (UTR) of the first exon. The Kpnl and Nhel restriction sites have been introduced into the $5^{\prime}$ end of the primers, for sub-cloning the amplicon in front of the luciferase ORF (grey box) contained into the pGL3 vector. Numbers indicate nucleotide position in the BoHV-4 full genome published sequence (GeneBank accession number: AF318573; Zimmermann et al. 2001). (b) IE2 promoter activity in BES cells at different time post transfection with pIE2prom-Luc or pGL3 empty vector. The data represent the mean relative luciferase units after normalizing with the cotransfected Renilla activity. Each reaction was done in quadruplicate, and each point represents the average \pm s.D. from three experiments $\left({ }^{*} P<0.001\right)$. transfection. Cells were harvested at different times after transfection and luciferase activity was measured. The IE2 promoter was activated within $12 \mathrm{~h}$ of transfection and it reached the maximum level by $48 \mathrm{~h}$ (Fig. 1b). The observation that $24 \mathrm{~h}$ was in the middle of the linear range of the promoter activation was used to select $24 \mathrm{~h}$ after transfection as the optimal time to analyze the IE2 promoter activity in subsequent experiments.

\section{Escherichia coli stimulates the BoHV-4 IE2 gene promoter}

The capability of bacteria to stimulate the BoHV-4 IE2 gene promoter was investigated using $E$. coli, because they are the most frequently bacterial isolates from the uterus of postpartum cattle with uterine disease (Olson et al. 1984, Sheldon \& Dobson 2004). Two strains of E. coli isolated from the uterus of postpartum cattle were used: E. coli 154 is a pathogenic strain associated with severe metritis and E. coli 361 was from a clinically normal animal. The bacteria were heat killed as described previously (Herath et al. 2006) and used at a range of concentrations spanning those present in the uterus of postpartum cattle (Dohmen et al. 2000, Williams et al. 2007). BES cells were challenged for $6 \mathrm{~h}$ with the bacteria, starting $24 \mathrm{~h}$ after transfection with pIE2prom-Luc or pGL3 empty vector and pTK-Renilla. Both strains of E. coli increased IE2 promoter activity in a concentration-dependent manner (Fig. 2a and b). Much of the host's immune response and pathology associated with $E$. coli is attributable to the bacterial endotoxin, lipopolysaccharide (LPS). LPS exerts its effect by binding to the TLR4/CD14/MD2 receptor complex, present in many cell types, including endometrial cells (Herath et al. 2006). To test whether LPS contributed to the activation of the IE2 promoter by E. coli, BES cells were treated for $6 \mathrm{~h}$ with $E$. coli, in the presence of different concentrations of the LPS inhibitor polymyxin $\mathrm{B}$ (PMB; Sigma), $24 \mathrm{~h}$ after transfection with pIE2prom-Luc or pGL3 empty vector and pTK-Renilla. PMB reduced the stimulatory effect of LPS (Fig. 2c and d).

\section{Specific stimulation of the BoHV-4 IE2 gene promoter by LPS}

To further determine the role of LPS in IE2 activation, the experiment was repeated with pure (O55:B5, Sigma) and ultrapure LPS (O111:B4, Invivogen) from different E.coli serotypes, at concentrations reflecting the range measured in the uterine lumen of postpartum cows (Williams et al. 2007). Both forms of LPS stimulated the IE2 promoter in a concentrationdependent manner (Fig. 3a and b). A GFP reporter construct for IE2 was used to confirm these observations (data not shown). Both forms of LPS increased BES fluorescence, indicating activation of the IE2 promoter. To determine whether the response was 
(a)



(c)

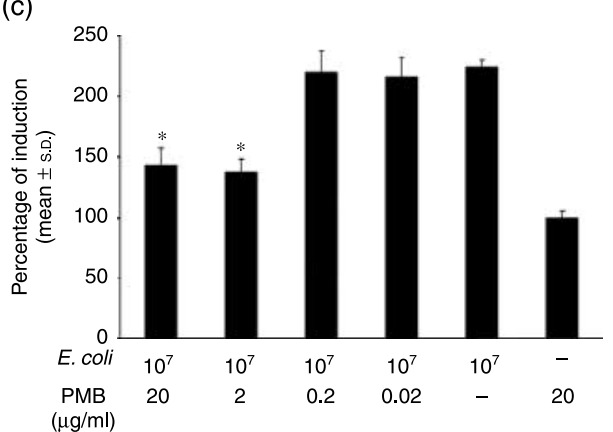

(b)

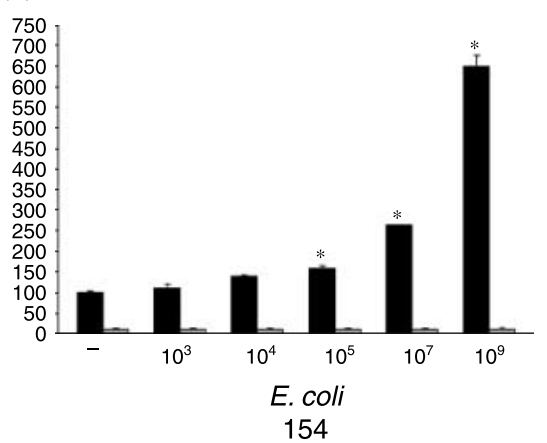

(d)

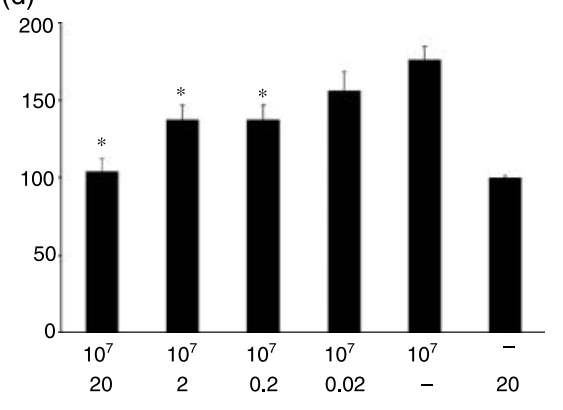

Figure 2 Transiently transfected BES cells with pIE2prom-Luc (black bars) or pGL3 (gray bars) empty vector for $24 \mathrm{~h}$. The cells were then stimulated for $6 \mathrm{~h}$ with $10^{3}, 10^{4}$, $10^{5}, 10^{7}$, or $10^{9} \mathrm{CFU} / \mathrm{ml}$ E. coli isolate 361 (a) or isolate 154 (b). The results are expressed as percentage of induction, where $100 \%$ is the untreated control $(-)$. Inhibition of the effect of $E$. coli isolate 361 (c) or isolate 154 (d) by increasing concentration of the LPS antagonist, polymyxin B (PMB). The data represent the mean relative luciferase units after normalizing with the cotransfected Renilla activity. Each reaction was done in quadruplicate, and each point represents the average \pm s.D. from three experiments. Values differ significantly from $E$. coliuntreated control (in a and $\mathrm{b}, * P<0.001$ ) and PMB-untreated control (in $\mathrm{c}$ and $\mathrm{d}$, $* P<0.001)$. associated with LPS and not contamination of the compounds, BES cells were treated with PMB before being challenged with LPS. The IE2 response to LPS was reduced by PMB (Fig. 3c and d), with the greater reduction for O111:B4 probably reflecting the greater purity of this preparation compared with O55:B5.

\section{$\mathrm{PGE}_{2}$ stimulates the $\mathrm{BoHV}$-4 IE2 gene promoter}

Prostaglandin $\mathrm{E}_{2}\left(\mathrm{PGE}_{2}\right)$ may also be involved in the activation of the IE2 promoter when there is co-infection of the uterus with BoHV-4 and E. coli. E. coli stimulates BES cell secretion of $\mathrm{PGE}_{2}$ and $6 \mu \mathrm{M} \mathrm{PGE}_{2}$ reactivated BoHV-4 replication in persistently infected bovine (a)
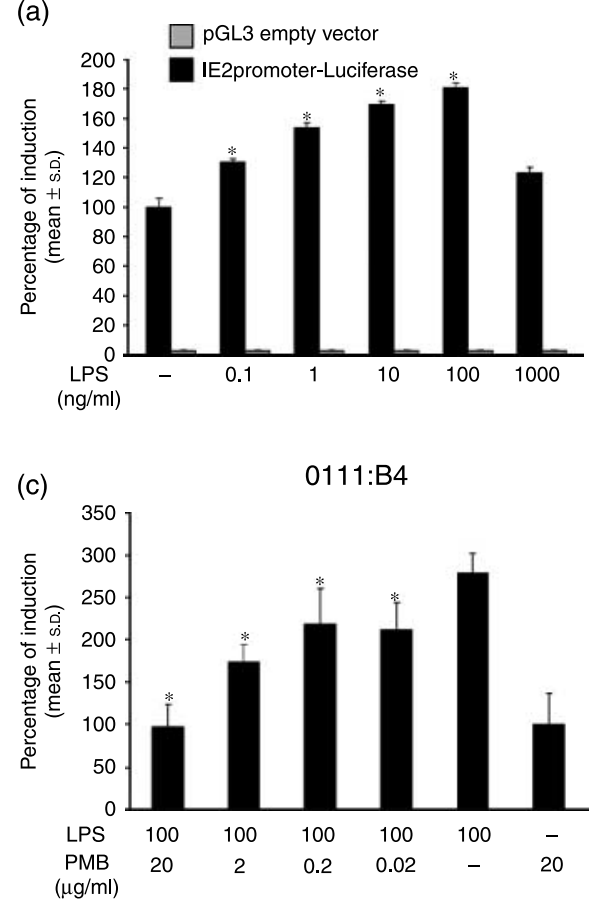

(b)

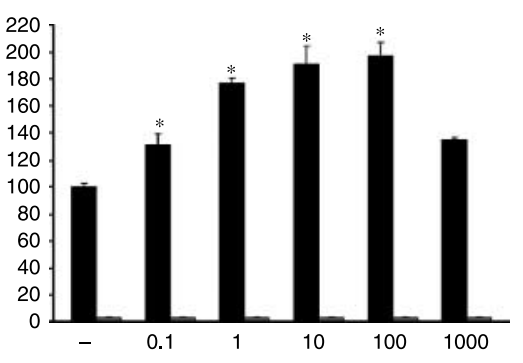

(d)

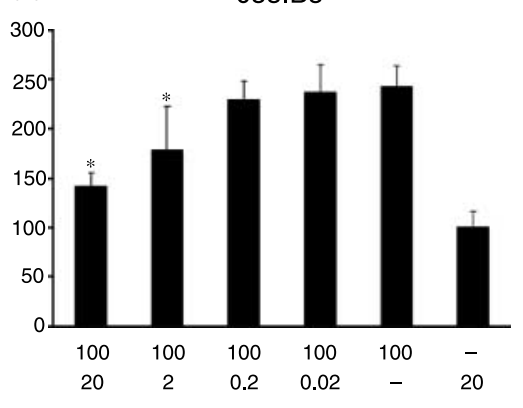

Figure 3 Transiently transfected BES cells with plE2prom-Luc (black bars) or pGL3 (gray bars) empty vector for $24 \mathrm{~h}$. The cells were than stimulated for $6 \mathrm{~h}$ with increasing concentrations of LPS O111:B4 (a) or O55:B5 (b). The results are expressed as percentage of induction, where $100 \%$ is the untreated control

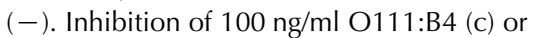
O55:B5 LPS (d) activity by increasing concentration of PMB. The data represent the mean relative luciferase units after normalizing with the cotransfected Renilla activity. Each reaction was done in quadruplicate, and each point represents the average \pm s.D. from three experiments. Values differ significantly from LPSuntreated control (in a and $\mathrm{b}, * P<0.001$ ) and PMB-untreated control (in $\mathrm{c}$ and $\mathrm{d},{ }^{*} P<0.001$ ). 
macrophages (Donofrio et al. 2005, Herath et al. 2006). Hence, BES cells were treated for $6 \mathrm{~h}$ with different concentrations of $\mathrm{PGE}_{2}$ (Sigma), $24 \mathrm{~h}$ after transfection with pIE2prom-Luc and pTK-Renilla. The IE2 promoter was stimulated by $0.4 \mu \mathrm{M} \mathrm{PGE}_{2}$, with maximal stimulation by $2-10 \mu \mathrm{M} \mathrm{PGE}_{2}$ (Fig. 4a).

\section{Independent and co-stimulatory effect of LPS and $P G E_{2}$ on the BoHV-4 IE2 gene promoter}

To explore whether IE2 activation by LPS and $\mathrm{PGE}_{2}$ is independent, BES cells were challenged with LPS, $\mathrm{PGE}_{2}$, or their combination, $24 \mathrm{~h}$ after transfection with pIE2prom-Luc and pTK-Renilla, and $12 \mathrm{~h}$ after treatment with a pan-cyclooxygenase (COX) inhibitor $(250 \mu \mathrm{M}$ indomethacin; Sigma) or vehicle. LPS and $\mathrm{PGE}_{2}$ independently stimulated IE2 expression as expected. However, the presence of indomethacin did not block the effect of LPS (Fig. 4b), so LPS may activate IE2 independent of $\mathrm{PGE}_{2}$. The combination of $\mathrm{LPS}$ and $\mathrm{PGE}_{2}$ appeared to exhibit a co-stimulatory effect of IE2.

\section{Discussion}

Bos taurus is particularly prone to uterine infection and metritis after parturition, (Sheldon \& Dobson 2004). The most commonly recognized uterine pathogen is $E$. coli (Olson et al. 1984, Dohmen et al. 2000, Sheldon et al. 2002, Sheldon \& Dobson 2004, Williams et al. 2007). However, BoHV-4 is also consistently associated with metritis. Bacteria may stimulate BoHV-4 replication of the virus following the recruitment from the bloodstream to the site of inflammation of macrophages persistently infected with BoHV-4. This theory may explain how BoHV-4 can be isolated from healthy animals in the absence of inflammation.

Assuming IE2 is the molecular master switch for BoHV-4 replication, the capability of endometrial cells to transactivate the IE2 promoter was previously investigated by transient transfection of an EGFP-labeled construct containing the IE2 gene promoter and electroporated into endometrial epithelial and stromal cells, BT, BEL, MDBK, and BEK cells. EGFP started to accumulate robustly as soon as $24 \mathrm{~h}$ after electroporation in the cytoplasm of stromal cells, in contrast to the other cell types where weak visible green cells appeared not before 3 days post electroporation (Donofrio et al. 2007a, 2007b). The present study provides evidence that bacterial co-infection is important for the activation of the IE2 gene promoter in BES cells, necessary to activate the BoHV-4 lytic replication associated with uterine disease. Bacterial contamination of the uterine lumen is ubiquitous in postpartum cattle (Sheldon \& Dobson 2004); BoHV-4 metritis is consistently associated with bacterial co-infection (Park \& Kendrick 1973, Castrucci et al. 1986, Mehrotra et al. 1986, Czaplicki \& Thiry 1998, Frazier et al. 2002, Monge et al. 2006, Nikolin et al. 2007). Bacterial infection stimulates PTGS2

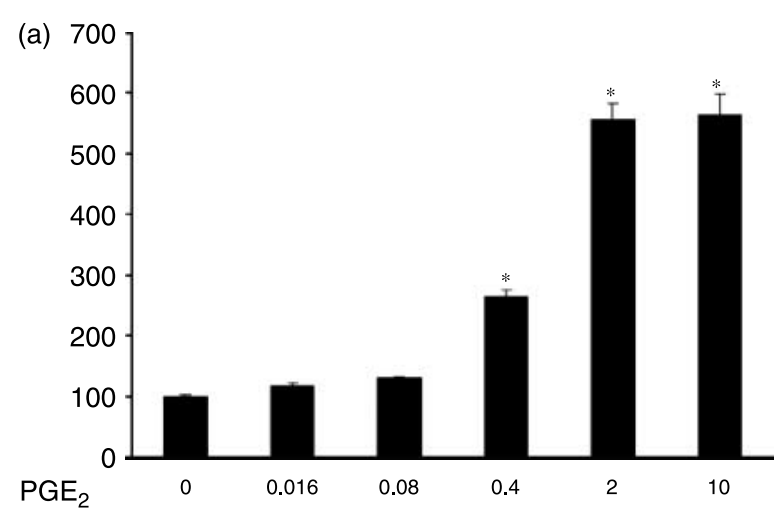

$(\mu \mathrm{M})$

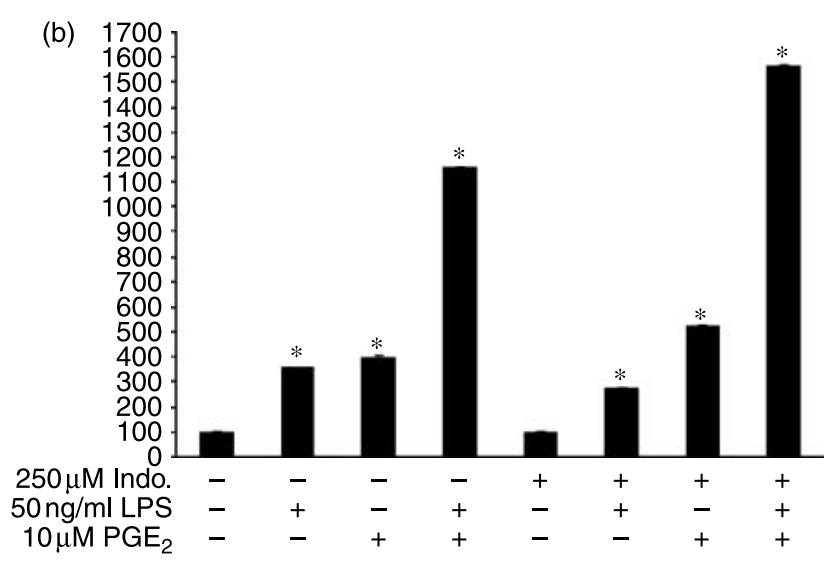

Figure 4 Transiently transfected BES cells with pIE2prom-Luc (black bars) for $24 \mathrm{~h}$. (a) The cells were then stimulated with increasing concentrations of $\mathrm{PGE}_{2}$ for $6 \mathrm{~h}$. The results are expressed as percentage of induction, where $100 \%$ is the untreated control $(-)$. (b) In a parallel experiment, BES cells were untreated or pre-treated with $250 \mu \mathrm{M}$ indomethacin and then stimulated with $\mathrm{PGE}_{2}$, LPS, or a combination of LPS and $P G E_{2}$. The data represent the mean relative luciferase units after normalizing with the cotransfected Renilla activity. Each reaction was done in quadruplicate, and each point represents the average \pm s.D. from three experiments $(* P<0.001)$.

(COX2) expression and production of $\mathrm{PGE}_{2}$ in bovine endometrial cells (Herath et al. 2006). The role of $\mathrm{PGE}_{2}$ on IE2 activation is particularly important in the uterus, as $E$. coli or LPS induces PTGS2 expression and $\mathrm{PGE}_{2}$ production by BES cells (Herath et al. 2006). Indeed, LPS stimulates sufficient $\mathrm{PGE}_{2}$ secretion $(\sim 0.3 \mu \mathrm{M})$ to activate IE2 expression. Furthermore, BoHV-4 also induces PTGS2 protein expression and $\mathrm{PGE}_{2}$ secretion in BES cells (Donofrio et al. 2007a, 2007b).

Here, we show that $E$. coli, $\mathrm{LPS}$, and $\mathrm{PGE}_{2}$ activate the BoHV-4 IE2 gene promoter, and this probably involves $\mathrm{PGE}_{2}$-dependent and -independent pathways. These observations provide a plausible mechanism underlying the rapid activation of viral replication in the bovine endometrium associated with uterine disease. Indeed, there could be a positive feedback loop between $\mathrm{PGE}_{2}$ production and viral replication, initiated by the bacterial co-infection. This mechanism could be 
important in other tissues other than the uterus, where bacterial and viral infections coexist. Identification and exploration of the underlying mechanisms of viralbacterial synergism will provide targets for prevention and treatment using drugs and vaccines.

\section{Materials and Methods \\ Reagents}

Purified LPS (from E. coli, O55:B5 and O111:B4), $\mathrm{PGE}_{2}$, indomethacin, and PMB were purchased from Sigma-Aldrich. Heat-killed E. coli isolate 361 and 154 were isolated from a normal animal and case of clinical bovine endometritis associated with pyrexia, respectively, as described (Sheldon et al. 2002).

\section{Endometrial cell isolation and primary cultures}

Six bovine uteri from post-pubertal, non-pregnant, BoHV-4 serum-negative animals with no evidence of genital disease were collected at a local abattoir immediately after slaughter and kept on ice until further processing in the laboratory. The physiological stage of the reproductive cycle for each genital tract was determined by observation of the ovarian morphology. Genital tracts with an ovarian stage I corpus luteum were selected for endometrial tissue and cell culture, and only the horn ipsilateral to the corpus luteum was used.

The endometrium was cut into strips and placed into serumfree RPMI-1640 (Sigma), supplemented with $50 \mathrm{IU} / \mathrm{ml}$ penicillin, $50 \mu \mathrm{g} / \mathrm{ml}$ streptomycin, and $2.5 \mu \mathrm{g} / \mathrm{ml}$ amphotericin B (Sigma), working under sterile conditions. The strips were then chopped into $1 \mathrm{~mm}^{3}$ pieces and placed into HBSS (Sigma) and used as previously described (Fortier et al. 1988) with the following modifications. Briefly, tissue was digested in $25 \mathrm{ml}$ sterile-filtered digestive solution, which was made by dissolving $50 \mathrm{mg}$ trypsin III (Roche), $50 \mathrm{mg}$ collagenase II (Sigma), $100 \mathrm{mg}$ BSA (Sigma), and $10 \mathrm{mg}$ DNase I (Sigma) in $100 \mathrm{ml}$ phenol red-free HBSS. Following a 1.5 -h incubation in a shaking water bath at $37^{\circ} \mathrm{C}$, the cell suspension was filtered through a $40 \mu \mathrm{m}$ mesh (Fisher Scientific, London, UK) to remove undigested material and the filtrate was resuspended in phenol red-free HBSS containing 10\% FBS (Sigma) and $3 \mu \mathrm{g} / \mathrm{ml}$ trypsin inhibitor (Sigma) (washing medium). The suspension was centrifuged at $100 \mathrm{~g}$ for $10 \mathrm{~min}$ and, following two further washes in washing medium, the cells were resuspended in RPMI- 1640 containing 10\% FBS, $50 \mathrm{IU} / \mathrm{ml}$ penicillin, $50 \mu \mathrm{g} / \mathrm{ml}$ streptomycin, and $2.5 \mu \mathrm{g} / \mathrm{ml}$ amphotericin B. The cells were plated at a density of $1 \times 10^{5}$ cells in $2 \mathrm{ml}$ per well using 24-well plates (Nunc, London, UK). To obtain separate stromal and epithelial cell populations, the cell suspension was removed $18 \mathrm{~h}$ after plating, which allowed selective attachment of stromal cells (Fortier et al. 1988). The absence of immune cells in the uterine cell cultures was confirmed by RT-PCR for the CD45 pan-leukocyte marker, as previously described (Herath et al. 2006). The culture media were changed every $48 \mathrm{~h}$ until the cells reached confluence. All cultures were maintained at $37^{\circ} \mathrm{C}, 5 \% \mathrm{CO}_{2}$ in air, in a humidified incubator.

\section{Plasmids}

The IE2 promoter region of the BoHV-4 genome (nucleotide 61 391-62 534; GenBank accession number AF318571; Zimmermann et al. 2001) was generated by PCR, using total DNA isolated from BoHV-4-infected MDBK cells as template and a pair of IE2 promoter primers (sense: $5^{\prime}$-AAACCCGGTACCGCCAGTGCCAAGCTTTTTAAG-3'; antisense: $5^{\prime}$-GGGAACTAGCTAGCCTGTTGTTCTGCTCCСТTTTA-3') containing an artificial Kpnl site on the $5^{\prime}$ end and a Nhel site on the $3^{\prime}$ end respectively.

One microgram sample DNA was amplified over 35 cycles, each cycle consisting of denaturation at $94{ }^{\circ} \mathrm{C}$ for $1 \mathrm{~min}$, primer annealing at $55^{\circ} \mathrm{C}$ for $1 \mathrm{~min}$, and chain elongation with High Fidelity PCR Enzyme Mix (Fermentas, St Leon-Rot, Germany) at $72{ }^{\circ} \mathrm{C}$ for $2 \mathrm{~min}$. PCR amplification was carried out in a final volume of $50 \mu \mathrm{l}$, containing $0.2 \mathrm{mM}$ deoxynucleoside triphosphate and $0.25 \mu \mathrm{M}$ of each primer. In the first cycle, the samples were denatured at $94{ }^{\circ} \mathrm{C}$ for $5 \mathrm{~min}$, and in the last cycle, the extension step was increased to $7 \mathrm{~min}$. The amplicon was column purified, Kpnl, Nhel digested, and sub-cloned into pGL3 Basic vector (Promega) to generate pIE2prom-Luc. pTKRenilla were obtained from Promega. All constructs were sequenced to guarantee the fidelity of the PCR products.

\section{Transient transfection}

Confluent BES cells in 24-well plates were co-transfected with $0.5 \mu \mathrm{g}$ plE2 prom-Luc or $0.5 \mu \mathrm{g}$ pGL3 empty vector, as a negative control and $0.05 \mu \mathrm{g}$ pRK-Renilla to normalize the efficiency of transfection, using lipofectamine (LTX) transfection reagent (Invitrogen) as suggested by manufacturer. Transfection mixture was prepared in DMEM without serum and antibiotics and left on the cells for $6 \mathrm{~h}$ at $37^{\circ} \mathrm{C}, 5 \% \mathrm{CO}_{2}$ in air, in a humidified incubator. After $6 \mathrm{~h}$, the transfection mixture was replaced with complete medium (RPMI-1640, 10\% FBS, $50 \mathrm{IU} / \mathrm{ml}$ penicillin, $50 \mu \mathrm{g} / \mathrm{ml}$ streptomycin, and $2.5 \mu \mathrm{g} / \mathrm{ml}$ amphotericin B) and left to recover for $18 \mathrm{~h}$ at $37^{\circ} \mathrm{C}, 5 \% \mathrm{CO}_{2}$ in air, in a humidified incubator. After $24 \mathrm{~h}$ of transfection, cells were treated with different reagents for period.

\section{Luciferase reporter assay}

Luciferase reporter assay was performed with a Dual Luciferase Reporter Assay System kit (Promega) with minor modifications. Following treatments, cells were washed with PBS, lysed with $100 \mu \mathrm{l}$ lysis passive buffer by freeze-thawing at $-80^{\circ} \mathrm{C}$. According to the manufacturer's specifications, $10 \mu \mathrm{l}$ of the cell lysate was added to $50 \mu \mathrm{LAR}$, and luciferase activity was determined with a Perkin-Elmer Victor ${ }^{3}$ Multilabel Counter (Perkin-Elmer, Milan, Italy). Individual assays were normalized for Renilla luciferase activity with a second reading, adding $50 \mu \mathrm{l}$ Stop \& Glo substrate.

\section{Statistical analysis}

Experiments were performed with four replicates at each time point and each experiment was repeated three times. Statistical differences were tested by ANOVA. 


\section{Declaration of interest}

The authors declare that there is no conflict of interest that could be perceived as prejudicing the impartiality of the research reported.

\section{Funding}

Sheldon is a BBSRC Research Development Fellow (Grant No. BB/D02028X/1). Donofrio was supported by a Royal Society International Incoming Short Visit.

\section{Acknowledgements}

We would like to thank the Italian Ministry of University and Scientific Research (Italian National Grant MIUR, PRIN 2005, 2005078885), the Fondazione Cariparma (Cassa di Risparmio di Parma, Italy).

\section{References}

Castrucci G, Frigeri F, Cilli V, Donelli G, Ferrari M, Chicchini U \& Bordoni E 1986 A study of a herpesvirus isolated from dairy cattle with a history of reproductive disorders. Comparative Immunology, Microbiology and Infectious Diseases 9 13-21.

Czaplicki G \& Thiry E 1998 An association exists between bovine herpesvirus-4 seropositivity and abortion in cows. Preventive Veterinary Medicine 33 235-240.

Dohmen MJW, Joop K, Sturk A, Bols PEJ \& Lohuis JACM 2000 Relationship between intra-uterine bacterial contamination, endotoxin levels and the development of endometritis in postpartum cows with dystocia or retained placenta. Theriogenology 54 1019-1032.

Donofrio G, Cavirani S, Taddei S \& Flammini CF 2004 Activation of bovine herpesvirus 4 lytic replication in a non-permissive cell line by overexpression of BoHV-4 immediate early (IE) 2 gene. Journal of Virological Methods 116 203-207.

Donofrio G, Martignani E, Cavirani S \& Flammini CF 2005 Exploiting persistent infection for selection of bovine herpesvirus 4 recombinants. Journal of Virological Methods 128 6-13.

Donofrio G, Herath S, Sartori C, Cavirani S, Flammini CF \& Sheldon IM 2007a Bovine herpesvirus 4 is tropic for bovine endometrial cells and modulates endocrine function. Reproduction 134 183-197.

Donofrio G, Martignani E, Sartori C, Vanderplasschen A, Cavirani S, Flammini CF \& Gillet L 2007b Generation of a transposon insertion mutant library for bovine herpesvirus 4 cloned as a bacterial artificial chromosome by in vitro MuA based DNA transposition system. Journal of Virological Methods 141 63-70.
Fortier MA, Guilbault LA \& Grasso F 1988 Specific properties of epithelial and stromal cells from the endometrium of cows. Journal of Reproduction and Fertility 83 239-248.

Frazier KS, Baldwin CA, Pence M, West J, Bernard J, Liggett A, Miller D \& Hines ME 2002 Seroprevalence and comparison of isolates of endometriotropic bovine herpesvirus-4. Journal of Veterinary Diagnostic Investigation 14 457-462.

Herath S, Fischer DP, Werling D, Williams EJ, Lilly ST, Dobson H, Bryant CE \& Sheldon IM 2006 Expression and function of Toll-like receptor 4 in the endometrial cells of the uterus. Endocrinology 147 562-570.

Mehrotra ML, Shucla DC \& Srivastava NC 1986 Isolation of a new herpesvirus from cases of reproductive disorders in cow. Indian Journal of Animal Sciences $\mathbf{5 6}$ 1196-1199.

Monge A, Elvira L, Gonzalez JV, Astiz S \& Wellenberg GJ 2006 Bovine herpesvirus 4-associated postpartum metritis in a Spanish dairy herd. Research in Veterinary Science 80 120-125.

Nikolin VM, Donofrio G, Milosevic B, Taddei S, Radosavljevic V \& Milicevic V 2007 First Serbian isolates of bovine herpesvirus 4 (BoHV-4) from a herd with a history of postpartum metritis. New Microbiologica 30 53-57.

Olson JD, Ball L, Mortimer RG, Farin PW, Adney WS \& Huffman EM 1984 Aspects of bacteriology and endocrinology of cows with pyometra and retained fetal membranes. American Journal of Veterinary Research $\mathbf{4 5}$ 2251-2255.

Park JB \& Kendrick JW 1973 The isolation and partila characterization of a herpesvirus from a case of bovine metritis. Archiv Für Die Gesamte Virusforschung 41 211-215.

van Santen VL 1993 Characterization of a bovine herpesvirus 4 immediateearly RNA encoding a homolog of the Epstein-Barr virus R transactivator. Journal of Virology 67 773-784.

Sheldon IM \& Dobson H 2004 Postpartum uterine health in cattle. Animal Reproduction Science 82-83 295-306.

Sheldon I, Noakes D, Rycroft A, Pfeiffer D \& Dobson H 2002 Influence of uterine bacterial contamination after parturition on ovarian dominant follicle selection and follicle growth and function in cattle. Reproduction 123 837-845. 10.1530/rep.0.1230837.

Williams EJ, Fischer DP, Noakes DE, England GCW, Rycroft A, Dobson H \& Sheldon IM 2007 The relationship between uterine pathogen growth density and ovarian function in the postpartum dairy cow. Theriogenology 68 549-559.

Zimmermann W, Broll H, Ehlers B, Buhk HJ, Rosenthal A \& Goltz M 2001 Genome sequence of bovine herpesvirus 4 , a bovine Rhadinovirus, and identification of an origin of DNA replication. Journal of Virology $\mathbf{7 5}$ 1186-1194.

Received 21 April 2008

First decision 21 May 2008

Accepted 23 June 2008 